the whole of the huge pharynx in the hyoid and branchial region, the pericardium being also partially enclosed in cartilage.

In the Chimeroids and Selachians, there is a very large development of cartilages in the lips, and also partly occluding the openings of the nasal pouches, which latter are inferior in position. Taking an ordinary shark, we find that, besides perfectly normal branchial arches, there is a series of rings which strengthen the septa between the pouches. There may be from one to three even over the first aborted cleft-the spiracle. On the hyoid and branchial arches they are large; those in the former being pectinate, but in the latter simple. Outside the extremities of these there is also a large styloid cartilage, which is dilated below and strengthens the outer edge of the septum. These bars are extrabranchials, and represent, in a distinct form, the main elements of the basketwork of the lamprey. Extrabranchials and labials are but little developed in Ganoids and Teleosteans, but reappear in considerable force in the Dipnoi, which have a Chimæroid relationship.

There are no labials in the Urodeles; but, as already mentioned, the gills are epiblastic in origin, and their subcartilaginous supports therefore, belong to the extrabranchial system. Larval Anura come very close to the lampreys in the structure of these superficial cartilages. In the tadpole of Dactylethra, the large upper labial is extended into a long oral palpus on each side. In all anurous larvæ, the suctorial disk is composed of two cartilages, which form a horse-shoe, and not a ring as in the lamprey; the upper labials are large, and number from one to four. These latter are transitory, and are followed, during metamorphosis, by new nasal valves. The branchial arches proper only exist in rudiment, but the pouches are strengthened by extrabranchials, which are all connected together as in the lamprey; the septal rays thus pass inwards from these, as pectinate processes. Another superficial cartilage appears during metamorphosis, which is at first cres. centic and then annular, and gives rise to the annulus tympanicus.

In the Sauropsida, we find small elements belonging to the nasal valve cartilages. Of these, there are two pairs in the Ophidia and one in the Lacertilia, supporting Jacobson's organ. They are not present in turtles and crocodiles, but in these the annulus tympanicus reappears. In many bircls, there is a pair of cartilages in the front part of the palate, which evidently correspond to those in the snake and lizard; in the Rallidæ there is an inferior labial in the mandible.

In Mammalia-even in man-the representatives of the nasal valve cartilages are found in the appendix ala nasi, which is formed of four pieces. In the pig there is probably only one. In all mammals there is a large band of cartilage obliquely overlapping Meckel's cartilage on each side of the head, which exactly resembles the inferior labial of a shark. In this case, however, their proportional sizes are reversed, the labial being much larger than Meckel's. The ramus of the jaw is formed by the grafting of the dentary bone on to this plate-a combination of the superficial cartilage and bone, which is also seen in both the upper and lower jaw of the frog. Besides the bony annulus, most mammals have a cartilaginous ring surrounding the bony one. On the front margin of the first (hyo-mandibular) cleft, there is also a true opercular cartilage, or branchiostegal ray-the tragus; this cartilage passes with a special fold of the skin behind the cleft, which develops into the

The limbs are included in this lecture, in order that they may be compared with and distinguished from the superficial cartilages (extra. branchials) of the pharynx. The latter are developed in a part which corresponds to the somatopleure or body-wall ; and their position, therefore, corresponds with that of the ribs. But the limb-girdles are developed between the skin and the ribs, the limbs being simply continuations of the girdles-developing, according to their type, into ichthyopterygium, or cheiropterygium. As already mentioned, the visceral arches arise in the splanchnopleure; and thus both girdles and limbs correspond to something altogether external-not only to branchial arches, with which they have been compared by Gegenbaur, but even to the extrabran. chials and ribs.

With regard to the external bony skeleton, the placoid scales of the Selachians are not influenced much by the endoskeleton. But in Ganoids, and still more in Teleostei, the bony scales are largely dominated-especially in the head and shoulder-by the parts whieh they protect. In the lower forms of fish (Selachians, Ganoids, etc.), the scales are ossifications of the whole skin (dermostoses); but, as we ascend, we gradually come to bony plates developed beneath the skin (parostoses, or splint-bones). These parts, which can only correspond to the innermost lamina of a placoid or ganoid scale, largely help to build up the cranium and face in all the Amniota, giving rise to the membrane bones forming the roof and sides of the skull. Deeper laminæ are called ectostoses-c.g., the shafts of the long bones, the
vertebral arches, etc.

\section{ETHER v. CHLOROFORM.}

\section{By T. PRIDGIN TEALE, M.B., F.R.C.S.,}

\author{
Surgeon to the General Infirmary at Leeds.
}

IT is confessedly difficult, perhaps even impossible, to settle by statistics the question of the relative danger of these two anresthetics; chiefly for the reason that, whilst we know pretty nearly how many deaths from each agent occur during the year, we have not the means of ascertaining the relative proportions of the cases in which each anæsthetic has been used.

Such being the case, it may be worth while to record the opinions of those who, having for a great number of years had experience of chloroform, have also for many years (in my own case, more than six years) almost abandoned it in favour of ether. I wish, therefore, to tender my conclusions for what they are worth, based, as they are, upon what I have seen in the practice of my colleagues and myself at the Leeds Infirmary, and upon my experience of anæsthetics in my private practice. My conclusions are as follows.

I. Ether, properly administered, is a much safer anæsthetic than chloroform. So much safer do I believe it to be, that I counsel every surgeon whom I can influence in the matter, to study the method of its right administration, and to let ether take the place of chloro. form. The exceptions I make in favour of chloroform are : in infants, in patients subject to asthma or chronic bronchitis, and also, perhaps, in cases of abdominal obstruction, with difficult breathing, in which an operation has to be performed.

2. When many operations have to be done in rapid succession, to use ether is a great economy of time. A good "etherist" can get most patients under its influence in from one and a half to two minutes, whereas, in my experience, chloroform must be given from six to fifteen minutes before an operation can be commenced. I am aware that chloroformists trained in Edinburgh usually administer chloroform more rapidly than those trained in English hospitals.

3. A patient under the influence of ether is far more passive, and therefore in a more convenient condition for operation, than one: under chloroform. As soon as the effect of chloroform is passing off, the patient becomes, as a rule, and often very suddenly, very sensitive to pain; whereas, in the case of ether, especially if the patient have been kept for some time under its influence, the return of sensibility to pain is very slow. In fact, a patient may become so far conscious as to converse with the surgeon whilst stitches are being placed in the wound, and at the same time be entirely unconscious of pain. This was not my experience of chloroform.

4. When ether is administered without food on the stomach, troublesome sickness is very rare.

5. In using ether, the safety and comfort of the patient, the rapidity of the ancesthesia, and the convenience of the surgion in operating, depend very directly upon the method of administration employed, and the manner in which the administrator does his work.

6. There are good methods of administration of ether and bad methods, and there are good and bad "etherists". The varying opinions of the value of ether which prevail in the profession probably depend very directly upon the varying methods and manners of administration.

7. It is a bad method to give ether "on a towel", as first taught us by Dr. Joy Jeffreys, to whom England is deeply indebted for his successful crusade in favour of ether. This involves a great waste of ether, ten to twenty ounces being required. The patient's lungs are chilled, and bronchial rî́les, struggling, and maniacal excitement not unfrequently result. I, along with my colleagues, commenced ether under this system as a duty, and by no means an agreeable one, and held on doubtfully when I suspected that some patients probably died from the effects of the chilling of the lungs.

8. It is a bad method to give ether with the American basket-work frame, which, though not much better than the towel, served a good purpose as a step to better things.

9. The good methods are those in which the patient breathes over ether into. an India-rubber bag, a method, I believe, introduced into practice by Dr. Ormsby of Dublin, and carried to further perfection by Mr. Clover. In this method, the patient breathes the same air over and over again for six or eight times, thereby economising the heat of the air-passages, economising ether, and enhancing the effect of the ether by partial asphyxia. My experience of the use of Clover's smaller inhaler, under good management, is this: $a$. A patient can generally be ready for operation in a minute and a half, sometimes in less than a minute; $b$. There is rarely any struggling; $c$. Noisy excitement hardly ever occurs-perhaps, in my private practice, 
once in a hundred times; $d$. N'âles in the trachea are but seldom heard; $c$. Instead of six or eight ounces of ether being used in a short operation, and sixteen to twenty in one lasting an hour or an hour and a half, half an ounce or less suffices for a short operation (such as "sphincter-stretching" or "iridectomy"), and two to three ounces for an operation of an hour's duration, such as colotomy or excision of a joint.

IO. The administration of ether by inferior methods is still too common, and was until recently prevalent in some of our larger hospitals.

I I. Even with Ormsby's or Clover's inhalers, there is an infinite variety of skill in different etherists.

12. In order to become a good etherist, the administrator must stady how to give ether, must watch the patient attentively whilst giving it, and during the earlier inhalations must very carefully and studiously adjust the anxsthetic to the sensations of the patient.

I3. A careful, attentive student, with tact, and not hard and unfeeling, can easily and in a short time be taught to give ether properly.

Since the adoption of Clover's inhaler, I have had singular freedom from anxiety about my anxsthetics-far greater freedom than in the previous period, when I had to depend upon chloroform.

Finally, I would say that this favourable opinion of ether is based upon my experience of its use by a series of very able administratorssome in the Leeds Infirmary, others whilst acting as my private clinical assistants. Speaking as a looker-on, rather than as an administrator, I should say that the chief points in the right administration of ether are: first, to overcome the nervous dread of the patient by applying the mouthpiece only; then to turn on the ether gently, until the glottis becomes tolerant and the patient is slightly unconscious; lastly, to complete the anxsthesia rapidly. In advising beginners, I compare the regulation of the quantity of ether to the "curve of harmonic progression".

\section{PERCUSSION AS A THERAPEUTIC AGENT IN NERVOUS DISEASES.}

\section{BY J. MORTIMER GRANVILLE, M.D.}

With the cognisance of the leading physiologists and neurologists in England and on the Continent, I have for some years past been employing carefully graduated and precisely applied percussion as a therapeutic agent in the treatment of nervous diseases and disturbances, on a principle of which the following statement, published by me in February I88I, may be taken as a brief exposition.

"As far back as $1862-3$, I was, in the course of certain clinical studies of mental and sensory phenomena, induced to believe that many forms of the sensation we call "pain" were, in fact, unneces. sary, and might be interrupted by appropriate mental and physical methods and appliances. My first observations were made in connection with the paroxysmal or recurrent pains accompanying the uterine contractions in the natural process of parturition. On May 4 th, 1864 Dr. Graily Hewitt was good enough to communicate the results of $\mathrm{my}$ experiments and to show certain apparatus, to the Obstetrical Society of London. In a paper On the Application of Extreme Cold as an Anodyne in the Pain attendant on Parturition, a short abstract of which will be found in the Lancet of July 9th, 1864. I contended that the sensations of pain experienced by the parturient woman were not invariably synchronous with what, for want of a better name, we term the "pains" of her labour; and from this and other premisses-for example, the circumstance that the sensation is commonly "referred" to some region more "or less remote from the contracting uterus, or the dilating external passages, in which the real seat of the pain might have been supposed to be located-I deduced that the pain attendant on labour is neuralgic in its character. I had constructed small boxes or chambers of such sizes and shapes as to admit of their being conveniently applied to the supposed seats of the pain. These were filled with freezing mixture, and the effect of sudden contact in some thirty cases was to arrest the sensation of pain without in the least degree lessening the force of the uterine contractions. The experiment was, of course, simply interesting as bearing on the nature of the pain, as this process was too troublesome to admit of its adoption in practice; albeit some of the persons on whom I had the opportunity of trying my method experienced such striking relief that, on subsequent occasions, I believe they asked that the measure might be repeated. Having thus far persuaded myself that this form of pain was neuralgic, and that if the nerve affected could be strongly impressed, so as to change its state of irritation, the pain would cease, I proceeded to try the effect of rapidly tapping the skin over the fifth nerve in ordinary facial neuralgia with a Bennett's percussion hammer, using the ivory pleximeter as a shield. The results obtained by this method were very remarkable. Still, I simply thought of arresting the morbid action by shock. Later on-it is only possible to sketch the outline of the inquiry-I was led, by the light thrown on Newton's doctrine of concords and discords by Grove's generalisation as to the correlation of forces, and, more recently, by Professor Tyndall's beautiful series of experiments with sensitive flames and musical burners, to believe that the results of the tapping were not, like the interruption with shock produced by the sudden application of cold, due to a mere arrest of the painful state of irritation into which the nerve had been thrown, but were, in fact, brought about by the extinguishment of some morbid - that is, either inordinate or disorderly - set of vibrations by the superimposition of another, incompatible or discordant, set of vibrations mechanically produced. With this notion, I set to work to devise an instrument which should give a known number of blows per second, and thus admit of this new phase of the inquiry being pushed further......

"The sensation produced by the application of the instrument over a healthy nerve, so situated as to be readily thrown into mechanical vibration, closely resembles the effect of a weak dose of the interrupted current of electricity, and if it be prolonged the vibration will extend its area, exciting first formication or tingling, then a sensation of numbness, and finally some twitching of the superficial muscles. A nervous headache, and even migraine, may be induced by the application of the percuteur to the frontal ridges or the margins of the orbit. By the interposition of a thin plate of metal, or even stiff paper, the vibration may be readily propagated through a considerable region of the surface of the body, and in time the deeper muscles will frequently begin to act. I have even produced an involuntary movement, not unlike tendon-reflex, by applying the percuteur for some time over the ligamentum patellæ or the margin of the patella. Still more notable has been the fact that, by laying a sheet of paper over the abdomen, and moving the percuteur slowly in large circles round the umbilicus, the intestines have seemed to be excited to vermicular movement, and the bowels commenced to act. These results have not been constant, but have occurred with sufficient frequency to indicate that the experiments already made are worthy to be repeated......

"I will take leave to say that I think these results go to support my theory that it is by the introduction of discord into the rhythm of the morbid vibrations of the painful "state" the change which brings relief in neuralgia is effected. To apply the percuteur with a high rate of blows per second will aggravate the morbid state when that is itself a series of rapid vibrations; and in the same way a low speed of percussion increases, instead of relieving, the pains of a low-pitched and slow "boring" or "grinding" sensation. Acute or sharp pain is, I believe, like a high note in music, produced by rapid vibrations, while a dull, heavy, or aching pain resembles a low note or tone, and is caused by comparatively slow vibrations. A slow rate of mechanical vibration will, therefore, interrupt the rapid nerve-vibration of acute pain, while quick mechanical vibration more readily arrests the slower. The aim -if I am right in my conjecture-should be to set up a new set of vibrations which shall internut or change the morbid set by intro. ducing discord. This is the principle. Failure in the application of this principle will, I believe, be found to explain the failure to put an end to the pain; and I have, accordingly, set as much scientific value on my failures as on my successes."

My method is, it will be seen from these extracts, based upon the hypotheses (I) that all nerve action, whether normal or morbid, is vibratile; and (2) that it is possible to influence and control abnormal vibrations-in the manner above described-by mechanical vibrations propagated to the nervous structures, in particular directions and at known rates of speed. It is not my present purpose to discuss these hypotheses, or the method in detail ; but I am anxious to re-state, and now affirm, certain propositions, founded on experience, which, in previous intimations of the progress and success of my experiments, $I$ submitted tentatively. They are these.

I. I have rarely failed, in a fairly large number of cases-many of them of several years' standing-to bring the cerebro-spinal and, sometimes directly at others in secondary circuits, the sympathetic, ganglia under control, by the application of my percuteur over, or in mecha. nical relation through the adjacent tissues with, those ganglia.

2. I have in no instance failed to produce activity of the bowels, even in cases of previously obstinate constipation; and in many in. stances I have succeeded, within a short period, in restoring the periodic evacuation of their contents without recourse to drugs. This success alone places the method on a footing of value in daily practice.

3. I can now, in result of my more recent experiments, propagate the vibrations I produce along the trunks and into the branches of most 